\title{
ORAL LICHENOID LESIONS AND ALLERGY TO DENTAL MATERIALS
}

\author{
Dagmar Ditrichova $^{a *}$, Simona Kapralova ${ }^{\mathrm{b}}$, Martin Tichy ${ }^{\mathrm{a}}$, Vlastislava Ticha ${ }^{\mathrm{c}}$, Jitka Dobesova ${ }^{\mathrm{a}}$, \\ Eva Justova ${ }^{\mathrm{d}}$, Miroslav Eber ${ }^{\mathrm{b}}$, Petr Pirek ${ }^{\mathrm{b}}$
}

a Department of Dermatology and Venereology, Faculty of Medicine and Dentistry, Palacky University Olomouc, I. P. Pavlova 6, 77520 Olomouc, Czech Republic

${ }^{b}$ Department of Dentistry, Faculty of Medicine and Dentistry, Palacky University Olomouc

c Department of Pathology, Faculty of Medicine and Dentistry, Palacky University Olomouc

a Department of Oral and Maxillofacial Surgery, Faculty of Medicine and Dentistry, Palacky University Olomouc

e-mail:dagmar.ditrichova@fnol.cz

Received: September 15, 2007; Accepted: November 5, 2007

Key words: Oral lichenoid lesions/Patch tests/Contact allergy/Dental materials/Amalgam

Background: Dental materials, oral hygiene products and food additives may cause contact allergic reactions in the mouth with varied clinical presentation. Oral lichenoid lesions (lichen planus-like lesions) can be induced by hypersensitivity to dental restorative metals, acrylates, flavorings and other substances.

Aim: The aim of this study was to demonstrate contact allergy to dental materials in patients with oral lichenoid lesions using patch tests.

Patients and methods: Routine patch tests with two sets of allergens - "European Standard“ and „Dental Screening“ (Chemotechnique Diagnostics, Sweden) supplemented with pulverized amalgam, iridium, indium, menthol, sorbic acid and platinum were done on a set of 25 patients with lichenoid lesions located on the buccal mucosa, tongue and lips. Application and interpretation of the tests were conducted according to ICDRG (International Contact Dermatitis Research Group).

Results: $15(60 \%)$ patients showed sensitization to 1 or more allergens, with a total of 31 positive reactions. The greatest frequency of positive reactions was to dental metals, with a total of 27 positive reactions. The order of tested metals according to frequency of positive reactions was mercury (6/25/24 \%), amalgam $(6 / 25 / 24 \%)$, nickel (4/25/16 \%), palladium (4/25/16\%), cobalt (3/25/12\%), gold (2/25/8 \%), chrome (1/25/4 \%), indium $(1 / 25 / 4 \%)$. The clinical relevance of the results with regard to the material's presence in the mouth was demonstrated in 11 (44\%) patients. In 9 patients, replacement of the positively tested materials led to healing or to significant regression of mucosal changes.

Conclusions: The results of the patch tests showed the possible contribution of contact sensitization in the pathogenesis of lichenoid manifestations in the oral cavity. Due to the premalignant character of these lesions, replacement of positively tested materials and follow up of these patients is advised.

\section{INTRODUCTION}

The oral cavity, including the lips, is constantly exposed to a large number of potentially irritating and sensitizing substances. About 10-15 different metals, as well as synthetic resin, topical treatments, disinfectants and other dental materials may act on the buccal mucosa during routine dental treatment ${ }^{1}$. Most dental materials used for dental fillings, fixed and removable replacements, orthodontic instruments etc. are intended for long-term use in the oral cavity and must satisfy strict biocompatibility specifications. Abroad, especially in Scandinavian countries, national registries have existed since the 1990's. These monitor the adverse effects of dental biomaterials on the oral mucosa and they study the occurrence of contact irritation and allergic reactions to specific materials $^{2,3}$. This issue has not yet been addressed in the Czech Republic.

The clinical manifestations of contact hypersensitivity in the mouth vary from subjective difficulties such as burning, pain and dryness of the mucosa (burning mouth syndrome) to objective changes in the form of nonspecific stomatitis and cheilitis with reddish, edematous mucosae, erosions and ulcers ${ }^{4-7}$. A more distinctive manifestation are lichenoid reactions usually localised on the buccal mucosa, tongue and lips ${ }^{8,9}$. These chronic changes are most often associated with long-term exposure of the oral mucosa to dental metals, and also to acrylates, composite materials, additives and other substances, which lead to the development of a delayed hypersensitivity reaction ${ }^{10,11}$. The premalignant character of these lesions is a more recent finding ${ }^{12-14}$.

The aim of this work was to investigate the proportion of contact allergies to dental materials in the etiopathogenesis of lichenoid changes in the oral cavity in a set of patients. Routine examination methods include patch tests, which consist of controlled exposure of an area of skin to a small amount of tested allergen in a non-toxic concentration ${ }^{15}$. 


\section{PATIENTS AND METHODS}

Between the years 2005-2006, and in co-operation with local dentists, 183 patients with various manifestations of oral discomfort were examined and they underwent epicutaneous testing. Based on history, clinical and histopathological examination, a diagnosis of lichenoid changes in the oral cavity was made in $25(13.6 \%)$ patients (23 women and 2 men, aged 41-74, average age 53.5 years). None of these patients exhibited skin manifestations of lichen planus. The average duration of the lesions prior to testing was 32 months (ranging from 4-72 months). The oral lesions were most often located on the buccal mucosa (19 patients), 4 patients also had concurrent lesions located on the lateral and dorsal tongue surface, 2 patients also had lesions on the lips. Most patients had reticular and plaque-like types of lesions, in 8 patients in combination with erosive type.

Standard testing substances (Chemotechnique Diagnostics, Sweden) authorized by the ICDRG (International Contact Dermatitis Research Group) were used to demonstrate contact hypersensitivity to dental materials and to other dental products ${ }^{16}$. As testing sets for contact hypersensitivity in the mouth, 2 basic allergen series are recommended: "European Standard", which includes 25 of the most frequent European allergens, and "Dental screening" with 25 of the most common oral allergens. After consultation with dentists, these sets were expanded to include pulverized amalgam, iridium, indium, platinum, menthol and sorbic acid. Concentrations and used vehicles (petrolatum, water) are shown in Table 1 and 2. The tested substances were applied on the skin of the back over a period of 48 hours and fixated by LohmannRauscher plaster to ensure occlusive conditions (Fig. 1). The results were recorded 30 minutes after plaster removal and again on the $3^{\text {rd }}$ and $7^{\text {th }}$ day as recommended by the ICDRG ${ }^{15,16}$. A skin reaction with erythema and effusion, possibly papulovesicles (eczema reaction), was considered a positive reaction (Fig. 2).

\section{RESULTS}

In a set of 25 patients with lichenoid oral manifestations, patch tests showed a positive reaction to one or more tested substances in 15 patients (60\%), with a total of 31 positive reactions. Negative reactions were found in 10 patients.

The most frequent positive tests were observed in dental metals, especially mercury $(19.3 \%)$ and amalgam (19.3\% of all positive reactions). Nickel exhibited $12.9 \%$, palladium $12.9 \%$, cobalt $9.7 \%$, gold $6.4 \%$ positive reactions. An overview of positive reactions is shown in Table 3.

Table 4 shows the individual positively tested substances and their association with materials present in the oral cavity. Clinically relevant allergens were found in 11 patients (44\%): mercury $6 x$, nickel $2 x$, palladium $2 x$, gold 2x, chrome 1x, EGDMA 1x. Indeterminate relevance

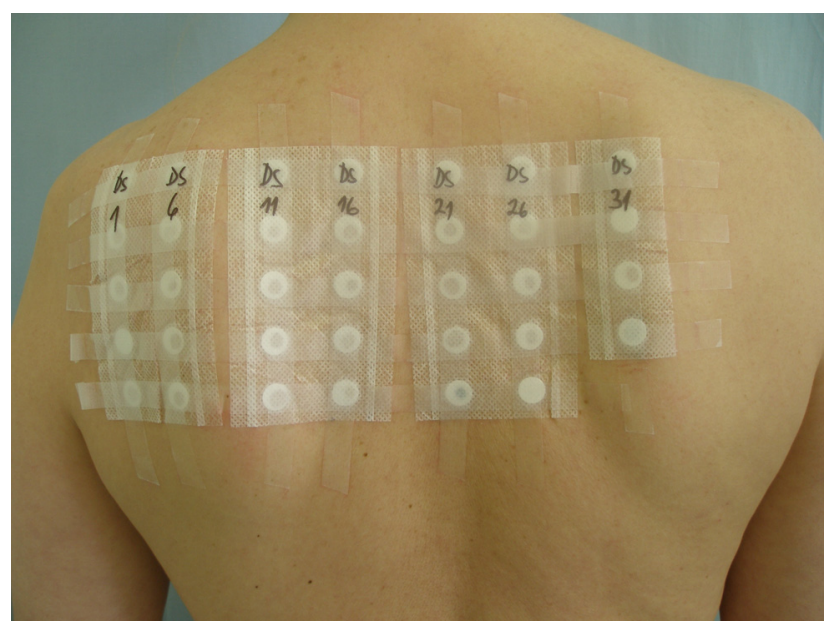

Fig. 1. Patch tests.

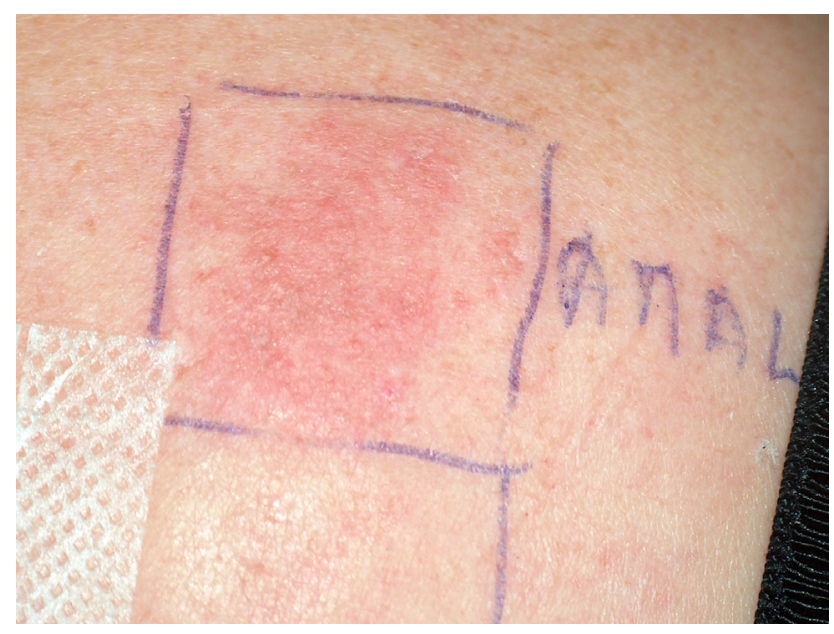

Fig. 2. Positive patch test for amalgam.

was found for colophony, balsam Peru, epoxy resin and certain metals.

Positive allergic reactions were observed after 48 hours of exposure in 12 patients, in 2 patients with positive mercury and amalgam the reaction was positive on the $3^{\text {rd }}$ day of exposure and 1 patient exhibited a positive test for gold with a 7 day latency.

\section{DISCUSSION}

Lichenoid manifestations are a fairly common finding in the oral cavity. Their etiopathogenesis is not quite clear, however, they are most commonly considered an immunopathological reaction to various etiological factors such as pharmaceuticals, graft vs host disease reaction and contact reaction to dental materials ${ }^{10,17,18}$. A number of studies have confirmed the frequent association between lichenoid reaction and contact hypersensitivity to dental metals. Healing or significant reduction in mucosal changes has been described in a large number of patients with a verified allergy to mercury once the amalgam fillings have 
Table 1. The list of tested allergens - European Standard series.

\begin{tabular}{|c|c|c|}
\hline & Compound & Concentration (\%) / Vehiculum \\
\hline 1. & Potassium dichromate & $0.5 \mathrm{pet}$ \\
\hline 2. & 4-Phenylenediamine base & 1.0 pet \\
\hline 3. & Thiuram mix & 1.0 pet \\
\hline 4. & Neomycin sulfate & 20.0 pet \\
\hline 5. & Cobalt chloride & 1.0 pet \\
\hline 6. & Benzocaine & 5.0 pet \\
\hline 7. & Nickel sulfate & 5.0 pet \\
\hline 8. & Clioquinol & 5.0 pet \\
\hline 9. & Colophony & 20.0 pet \\
\hline 10. & Paraben mix & 16.0 pet \\
\hline 11. & N-Isopropyl-N-phenyl-4-phenylenediamine & 0.1 pet \\
\hline 12. & Wool alcohols & 30.0 pet \\
\hline 13. & Mercapto mix & 2.0 pet \\
\hline 14. & Epoxy resin & 1.0 pet \\
\hline 15. & Balsam Peru & 25.0 pet \\
\hline 16. & 4-tert-Butylphenolformaldehyde resin PTBP & 1.0 pet \\
\hline 17. & 2-Mercaptobenzothiazole & 2.0 pet \\
\hline 18. & Formaldehyde & $1.0 \mathrm{aq}$ \\
\hline 19. & Fragrance mix & 8.0 pet \\
\hline 20. & Sesquiterpenelactone mix & 0.1 pet \\
\hline 21. & Quaternium 15 & 1.0 pet \\
\hline 22. & Primin & 0.01 pet \\
\hline 23. & Kathon CG & $0.01 \mathrm{aq}$ \\
\hline 24. & Budesonide & 0.01 pet \\
\hline 25. & Tixocortol-21-pivalate & 0.1 pet \\
\hline
\end{tabular}

Pet $=$ petrolatum, $\mathrm{Aq}=$ aqua

Table 2. The list of tested allergens - Dental Screening and additional substances.

\begin{tabular}{|c|c|c|}
\hline & Compound & $\begin{array}{c}\text { Concentration (\%) / } \\
\text { Vehiculum }\end{array}$ \\
\hline 1 & Methyl methacrylate MMA & 2.0 pet \\
\hline 2 & Triethyleneglycol dimethacrylate TREGDMA & 2.0 pet \\
\hline 3 & Urethane dimethacrylate UEDMA & 2.0 pet \\
\hline 4 & Ethyleneglycol dimethacrylate EGDMA & 2.0 pet \\
\hline 5 & 2,2-bis(4-(2-Hydroxy-3-methacryloxypropoxy)phenyl) propane BIS-GMA & 2.0 pet \\
\hline 6 & N,N-Dimethyl-4-toluidine & 5.0 pet \\
\hline 7 & 2-Hydroxy-4-methoxybenzophenone & 10.0 pet \\
\hline 8 & 1,4-Butanedioldimethacrylate BUDMA & 2.0 pet \\
\hline 9 & 2,2-bis(4-Methacryloxy)phenyl propane BIS-MA & 2.0 pet \\
\hline 10 & Mercury & 0.5 pet \\
\hline 11 & 2-Hydroxyethylmethacrylate 2-HEMA & 2.0 pet \\
\hline 12 & Goldsodiumthiosulfate & 2.0 pet \\
\hline 13 & Eugenol & 2.0 pet \\
\hline 14 & N-Ethyl-4-toluenesulfonamide & 0.1 pet \\
\hline 15 & 4-Tolyldiethanolamine & 2.0 pet \\
\hline 16 & Copper sulfate & 2.0 pet \\
\hline 17 & Methylhydroquinone & 1.0 pet \\
\hline 18 & Palladium chloride & 2.0 pet \\
\hline 19 & Aluminum chloride & 2.0 pet \\
\hline 20 & Camphoroquinone & 1.0 pet \\
\hline 21 & N,N-Dimethylaminoethyl methacrylate DMAEMA & 0.2 pet \\
\hline 22 & 1,6-Hexanediol diacrylate HDDA & 0.1 pet \\
\hline 23 & 2(2-Hydroxy-5-methyl-phenyl)benzotriazol (Tinuvin P) & 1.0 pet \\
\hline 24 & Tetrahydrofurfuryl methacrylate THFMA & 2.0 pet \\
\hline 25 & Tin & 50.0 pet \\
\hline 26 & Amalgam pulv. & 5.0 pet \\
\hline 27 & Sorbic acid & 2.0 pet \\
\hline 28 & Menthol & 2.0 pet \\
\hline 29 & Iridium chloride & 1.0 pet \\
\hline 30 & Indium chloride & $10.0 \mathrm{aq}$ \\
\hline 31 & Amonium tetrachloroplatinate & $0.25 \mathrm{aq}$ \\
\hline
\end{tabular}


been removed ${ }^{8,9,19}$. Dunsche described a regression in the manifestation of lichenoid changes after amalgam substitution in $97 \%$ of 134 patients, independent of results of epicutaneous testing ${ }^{20}$. He also experimentally confirmed the possible locally toxic effect of amalgam and the significance between a close topographical relationship between artificial material and pathological manifestation on the mucosa $^{21}$.

The oral cavity is a specific environment where chemical and electrochemical corrosion with saliva acts as an electrolyte. The resulting galvanic currents and corrosion processes may lead to the release of ions and their complexes even from stable dental metals, and these may act as haptens in the process of sensitization ${ }^{6,22}$. Other significant corrosive products in amalgam include copper and tin, which may also be a cause of lichenoid mucosal

Table 3. Positive reactions of patch tests in oral lichenoid lesions.

\begin{tabular}{|l|c|c|}
\hline \multicolumn{1}{|c|}{ Allergens } & $\begin{array}{c}\text { positive } \\
\text { reactions }\end{array}$ & $\%$ \\
\hline Mercury & 6 & 19.3 \\
\hline Amalgam & 6 & 19.3 \\
\hline Nickel & 4 & 12.9 \\
\hline Palladium & 4 & 12.9 \\
\hline Cobalt & 3 & 9.7 \\
\hline Gold & 2 & 6.4 \\
\hline Chromium & 1 & 3.2 \\
\hline Indium & 1 & 3.2 \\
\hline EGDMA & 1 & 3.2 \\
\hline Balsam Peru & 1 & 3.2 \\
\hline Colophony & 1 & 3.2 \\
\hline Epoxy resin & 1 & 3.2 \\
\hline Total & 31 & 100 \\
\hline
\end{tabular}

Table 4. Patients with positive patch tests, the sources of sensitization.

\begin{tabular}{|c|l|l|}
\hline Patient & Positive allergens & Sources of sensitization, materials \\
\hline 1. & Mercury, Amalgam & amalgam fillings \\
\hline 2. & Mercury, Amalgam & amalgam fillings \\
\hline 3. & Mercury, Amalgam & amalgam fillings \\
\hline 4. & Nickel, Palladium & fixed replacement, white metal \\
\hline 5. & Nickel, Chromium & white metal crowns and bridges, Remanium \\
\hline 6. & Mercury, Amalgam & amalgam fillings \\
\hline 7. & Nickel, Palladium, Cobalt & uncertain \\
\hline 8. & Gold, Indium & Gold crowns, indium - uncertain \\
\hline 9. & Mercury, Amalgam & amalgam fillings \\
\hline 10. & Nickel, Cobalt & uncertain \\
\hline 11. & Cobalt, Palladium & uncertain \\
\hline 12. & Gold, Palladium & Gold crowns, Aurix \\
\hline 13. & EGDMA & composite resin crowns \\
\hline 14. & Colophony, Epoxy resin & uncertain \\
\hline 15. & Mercury, Amalgam, Balsam Peru & amalgam fillings, Balsam Peru - uncertain \\
\hline & & \\
\hline
\end{tabular}

changes $^{6,20}$. Aside from amalgam, other metals, such as gold, palladium, nickel, chrome and cobalt may induce oral lichenoid mucositis ${ }^{23-25}$.

In our set of patients, the greatest frequency of sensitization was to dental metals. 6 patients tested positively for mercury and amalgam and the clinical relevance was confirmed by the healing of lichenoid manifestations upon removal of amalgam fillings in 4 patients and significant improvement after 4 months in 1 patient. One patient (no. 15) refused to exchange the amalgam, and was advised to limit contact with the also positively tested balsam Peru. One patient (no. 12) with crowns of gold alloy (Aurix) improved significantly after replacing the gold crowns with non-metal ceramic materials. Another patient refused to replace the gold material. One patient (no. 4) with a fixed replacement of white metal and one patient (no. 5) with crowns and dental bridges of white metal (Remanium) significantly improved 6 months following the replacement. The remaining patients with positive tests for nickel, palladium, cobalt and colophony with epoxy resin, the actual source of sensitization was not demonstrated in the mouth, although patients were informed about their latent allergy and told to limit contact with these substances. Patient no. 13 with a positive reaction to monomer EGDMA (ethyleneglycoldimethacrylate) improved significantly 3 months after replacing crowns made of composite resin.

There is currently little information on the relationship between lichenoid reactions and synthetic resins ${ }^{18,26}$. These modern so-called esthetic materials have only lately come to the forefront; although in some countries they have almost completely replaced amalgam and are currently the primary dental restoration material ${ }^{27,28}$. In a set of 1322 dental patients in Sweden, epicutaneous tests were positive for (meth)acrylates in $2.3 \%$ and in a set of dental personnel they were positive in $5.8 \%$, which shows the significant sensitizing potential of these substances ${ }^{28}$. 


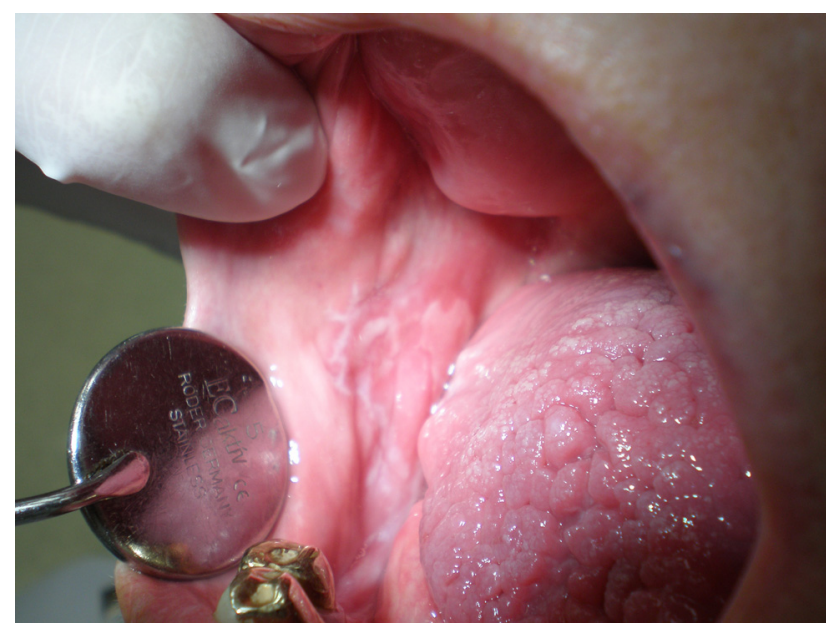

Fig. 3. Oral lichenoid lesions on the buccal mucosa

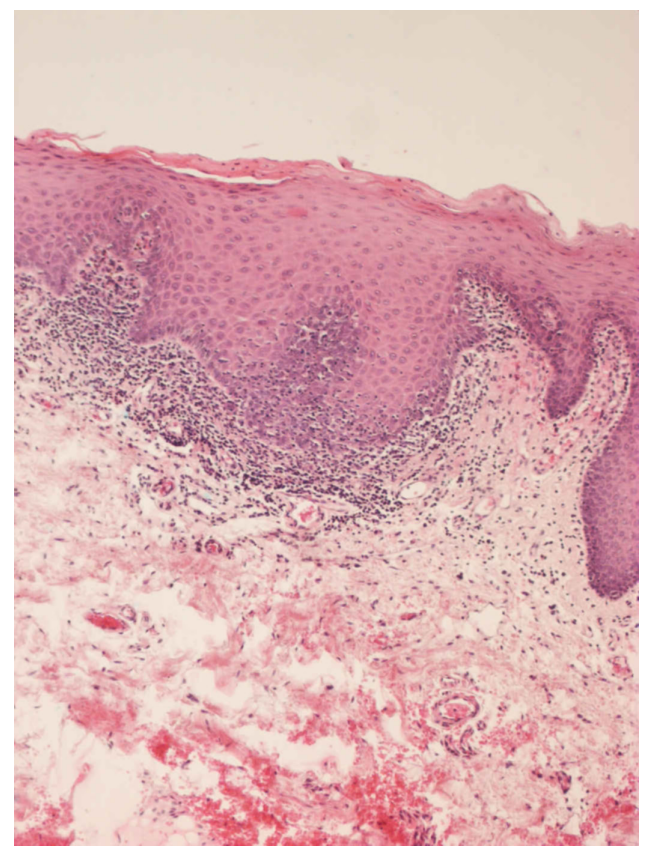

Fig. 5. Hematoxylin-eosin staining (x100). Oral lichenoid reaction

2-HEMA, EGDMA and BIS-GMA were recommended as screening allergens and correctly performed testing with an examination of the skin reaction after 1 week was emphasized. $16 \%$ of the positive results were not noted until the $7^{\text {th }}$ day after test application ${ }^{29}$.

Besides dental materials, a number of topical substances including phytotherapy, oral cosmetics, various food products and beverages along with additives may trigger an adverse reaction on the oral mucosa. Aside from nonspecific contact stomatitis and cheilitis, these substances may also be the source of lichenoid manifestations ${ }^{15,30}$. While an undisturbed oral mucosa with normal salivation is characterized by a certain resistance and regeneration ability, decreased saliva production, microbial mucosal colonization, mechanical trauma and long-term exposure to irritation and allergen-like substances disrupt its barrier

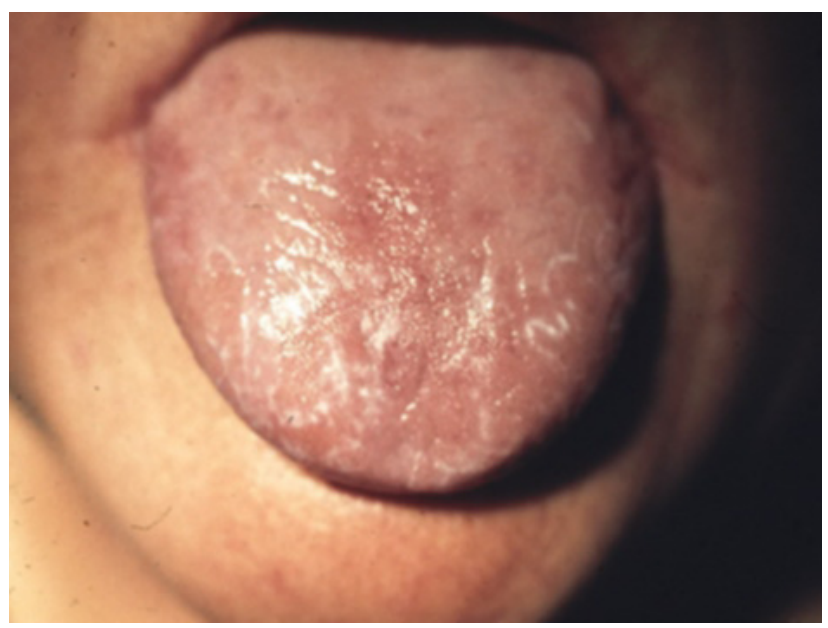

Fig. 4. Oral lichenoid lesions on the tongue

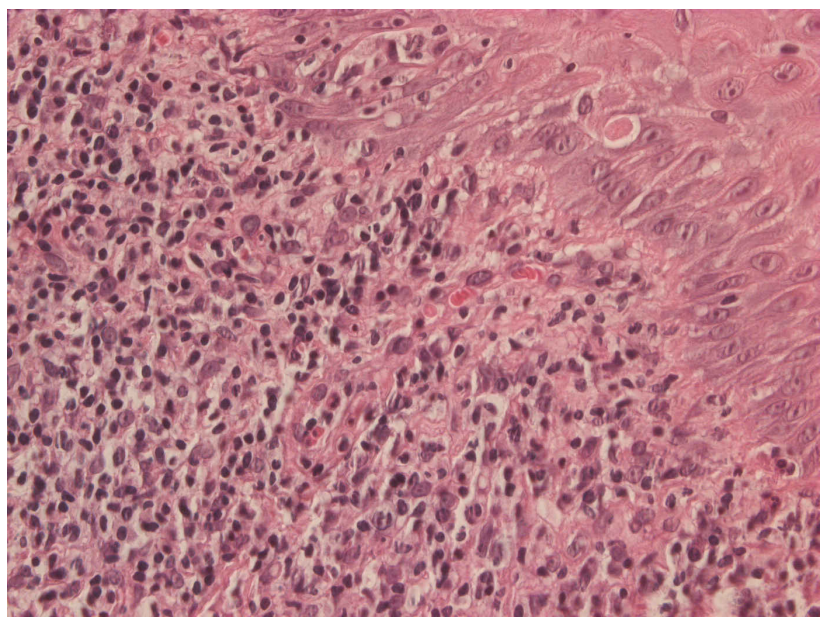

Fig. 6. Hematoxylin-eosin staining (x400). Detail of oral lichenoid lesion with Civatte body in the basal layer of the epidermis

function and create conditions for the development of a delayed hypersensitivity reaction ${ }^{15}$. Exposure to derivatives of cinnamon acid contained in toothpaste, chewing gum and sweets leads to lichenoid changes on the buccal mucosa and tongue ${ }^{11}$. Menthol and peppermint found in oral hygiene products, as well as in teas, liquors, gum, etc may induce intraoral erosions and lichenoid changes ${ }^{31}$. Eugenol from clove oil, popular in stomatology for its disinfecting and aromatizing qualities may have a similar effect on the mucosa ${ }^{32}$. Balsam Peru is a screening allergen for aromatizing substances and may cause undetected sensitization to common non-alcoholic beverages, vermouths, teas, spices, in oral cosmetics, etc ${ }^{30}$. In patient no. 15 with amalgam fillings, tests were positive for mercury, amalgam and balsam Peru. It was difficult to establish the test relevance of balsam Peru owing to its ubiquity. Removal of 
the amalgam fillings was recommended, as well as limited contact with this natural resin.

Diagnosis of oral lichenoid changes is based on detailed history, clinical examination and histopathological identification. A number of clinical forms have been described. The most common consists of reticular lesions followed by plaque-like, papulous, atrophic, bullous and erosive forms ${ }^{33}$, 34. Manifestation is usually asymptomatic, pain is a result of atrophic and erosive changes. Most patients in our sample had distinct whitish-grey reticular focuses on the buccal mucosa, on the dorsal and lateral tongue surfaces, also on the lips in 2 patients (Fig. 3, 4). In one-third of patients, these were combined with the erosive form.

Performing a histopathological examination is important to exclude other mucosal diseases such as bullous diseases, leukoplakia, lupus erythematosus, tumours, etc. Micromorphological changes typically include focal hyperkeratosis or parakeratosis, irregular acanthosis and liquefaction degeneration of the basal layer with a bandlike lymphocytic infiltrate high in the lamina propria. Eosinophilic Civatte bodies representing degenerated basal layer cells are characteristic (ref. ${ }^{8,34}$ ) (Fig. 5, 6) . However, it is impossible to differentiate between idiopathic lichen planus and lichenoid contact allergic manifestations based solely on these histopathological criteria $^{9,10,13,35,36}$. A correctly performed biopsy in the oral cavity, sufficient sample size and its proper orientation, material fragmentation or collection from an area of chronic ulceration with mycotic and microbial superposition is a common problem ${ }^{9}$. In our sample of 25 patients, histopathological examination was compatible with clinical diagnosis of oral lichenoid manifestation in 18 cases. In the remaining 7 patients with a clinically typical form, biopsy described only non-specific inflammatory changes.

Skin tests should follow clinical and microscopic examination. In case of positivity, it is recommended that the tested materials be removed from the oral cavity, or at least partially replaced in areas of close contact between dental material and oral mucosa.

Close interdisciplinary co-operation with dentists is necessary for the proper identification of potential allergens in the used dental materials. The ensuing replacement of suspect dental materials and other substances in the oral cavity is often not easy and is not always accepted by the patient. On the other hand, oral lichenoid lesions associated with contact hypersensitivity, especially to dental metals, are a possible risk factor for the development of squamous cell carcinoma of the mouth ${ }^{12,14}$. In ten out 11 patients with intraoral carcinoma, patch tests revealed hypersensitivity to gold, mercury, silver and copper ${ }^{12}$.

\section{CONCLUSIONS}

Skin tests are the only relevant examination method for the detection of a contact hypersensitivity reaction, valid even from a forensic viewpoint. They are irreplaceable in excluding pre-existing allergies to restoration mate- rials, especially prior to an extensive procedure in the oral cavity. In the case of lichenoid mucosal manifestations, epicutaneous tests to confirm suspect intraoral allergens, which may play a role in the pathogenesis of these chronic mucosal changes, are a stress-free examination method for the patients. In some cases, a locally toxic effect of dental materials on the oral mucosa cannot be excluded, and therefore in severe, especially erosive forms, where there is close contact between mucosa and dental metals, their replacement with other materials is recommended.

\section{ACKNOWLEDGEMENT}

This work was supported by the IGA Ministry of Health CR grant NR 8379-3.

\section{REFERENCES}

1. Ditrichová D, Dobešová J, Kaprálová S, Eber M, Steigerová H. Nejčastější kontaktní alergeny ústní dutiny a rtů. Čes Stomat 2007; 107:39-45.

2. Lygre GB, Gjerdet NR, Gronningsaeter AG, Björkman L. Reporting on adverse reactions to dental materials - intraoral observations at a clinical follow-up. Community Dent Oral Epidemiol 2003; 31:200-6.

3. Lygre GB, Gjerdet NR, Björkman L. A follow-up study of patiens with subjective symptoms related to dental materials. Community Dent Oral Epidemiol 2005; 33:227-34.

4. Torgerson RR, Davis MD, Bruce AJ, Farmer SA, Rogers RS 3rd. Contact allergy in oral disease. J Am Acad Dermatol 2007; 57:31521.

5. Koch P, Bahmer FA. Oral lesions and symptoms related to metals used in dental restorations: a clinical, allergological and histological study. J Am Acad Dermatol 1999; 41:422-30.

6. Gawkrodger DJ. Investigation of reactions to dental materials. $\mathrm{Br}$ J Dermatol 2005; 153:479-85.

7. Dobešová J, Ditrichová D, Kaprálová S, Pírek P, Eber M. Kontaktní alergická cheilitida. Derma 2007; 7:12-6.

8. Laeijendecker R, Dekker SK, Burger PM, Mulder PGH, Van Joost T, Neumann MHA. Oral Lichen Planus and Allergy to Dental Amalgam Restorations. Arch Dermatol 2004; 140:1434-8.

9. Thornhill MH. Oral lichenoid lesions and amalgam fillings. Evid Based Dent 2006; 7:74-5.

10. Edwards PC, Kelsch R. Oral Lichen Planus: Clinical Presentation and Management. J Can Dent Assoc 2002; 68:494-9.

11. Hoskyn J, Guin JD. Contact allergy to cinnamal in a patient with oral lichen planus. Contact Dermatitis 2005; 52:160.

12. Hougeir FG, Yiannias JA, Hinni ML, Hentz JG, el-Azhary RA. Oral metal contact allergy: a pilot study on the cause of oral squamous cell carcinoma. Int J Dermatol 2006; 45:265-71.

13. Ismail SB, Kumar SKS, Zain RB. Oral lichen planus and lichenoid reactions: etiopathogenesis, diagnosis, management and malignant transformation. J Oral Sci 2007; 49:89-106.

14. van der Meij EH, Mast H, van der Waal I. The possible premalignant character of oral lichen planus and oral lichenoid lesions: A prospective five-year follow-up study of 192 patients. Oral Oncol 2007; 43:742-8.

15. Rietschel RL, Fowler JF Jr. Fisher's contact dermatitis. $5^{\text {th }}$ ed. Philadelphia: Lippincott Williams \& Wilkins; 2001.

16. Catalogue Patch Test Products. Chemotechnique Diagnostics. Sweden: 2007.

17. Wong L, Freeman S. Oral lichenoid lesions (OLL) and mercury in amalgam fillings. Contact Dermatitis 2003; 48:74-9.

18. Yiannias JA, Azhary RA, Hand JH, Pakzad SY, Rogers RS III. Relevant contact sensitivities in patients with the diagnosis of oral lichen planus. J Am Acad Dermatol 2000; 42:177-82. 
19. Athavale PN, Shum KW, Yeoman CM, Gawkrodger DJ. Oral lichenoid lesions and contact allergy to dental mercury and gold. Contact Dermatitis 2003; 49:264-5.

20. Dunsche A, Kästel I, Terheyden H, Springer ING, Christophers E, Brasch J. Oral lichenoid reactions associated with amalgam: improvement after amalgam removal. Br J Dermatol 2003; 148:706.

21. Dunsche A, Frank MP, Lüttges J, Acil Y, Brasch J, Christophers E, Springer ING. Lichenoid reactions of murine mucosa associated with amalgam. Br J Dermatol 2003; 148:741-8.

22. Valentová K. Chemické vlastnosti dentálních materiálů. Olomouc: Univerzita Palackého; 2006.

23. Tvinnereim HM, Lundekvam BF, Morken T, Berge ME, Björkman L. Allergic contact reactions to dental gold. Contact Dermatitis 2003; 48:288-9.

24. Laine J, Kalimo K, Happonen RP. Contact allergy to dental restorative materials in patients with oral lichenoid lesions. Contact Dermatitis 1997; 36:141-6.

25. Möller H. Dental gold alloys and contact allergy. Contact Dermatitis 2002; 47:63-6.

26. Auzerie V, Mahé E, Marck Y, Auffret N, Descamps V, Crickx B. Oral lichenoid eruption due to methacrylate allergy. Contact Dermatitis 2001; 45:241.

27. Henriks-Eckerman ML, Suuronen K, Jolanki R, Alanko K. Methacrylates in dental restorative materials. Contact Dermatitis 2004; 50:233-7.
28. Goon ATJ, Isaksson M, Zimerson E, Goh CL, Bruze M. Contact allergy to (meth)acrylates in the dental series in southern Sweden: simultaneous positive patch test reaction patterns and possible screening allergens. Contact Dermatitis 2006; 55:219-26.

29. Isaksson M, Lindberg M, Sundberg K, Hallander A, Bruze M. The development and course of patch-test reactions to 2-hydroxyethyl methacrylate and ethyleneglycol dimethacrylate. Contact Dermatitis 2005; 53:292-7.

30. Urbanček S, Dastychová E, Buchvald D, Vocilková A. Kontaktné alergény v pracovnom a životnom prostredí. Banská Bystrica: Gutenberg; 2005.

31. Clayton R, Orton D. Contact allergy to spearmint oil in a patient with oral lichen planus. Contact Dermatitis 2004; 51:314-5.

32. Fujita Y, Shimizu T, Nishie W, Shimizu H. Contact dermatitis due to eugenol used to treat oral lichen planus. Contact Dermatitis 2003; 48:285-6.

33. Thorn JJ, Holmstrup P, Rindum J, Pindborg JJ. Course of various clinical forms of oral lichen planus. A prospective follow-up study of 611 patients. J Oral Pathol 1988; 17:213-8.

34. Benáková N, Štork J. Lichen planus a lichenoidní reakce. Čes-slov Derm 2005; 80:65-75.

35. van der Meij EH, Schepman KP, Plonait DR, Axéll T, van der Waal I. Interobserver and intraobserver variability in the clinical assessment of oral lichen planus. J Oral Pathol 2002; 31:95-8.

36. van der Meij EH, van der Waal I. Lack of clinicopathologic correlation in the diagnosis of oral lichen planus based on the presently available diagnostic criteria and suggestions for modifications. J Oral Pathol 2003; 32:507-12. 